\title{
Hydration enthalpy for synthetic and cation exchanged A-type zeolites with special reference to zeolite heat pump media
}

\author{
Toshihiro KASAI*, Hiroshi MAEDA*, Kousuke MATSUI*, Dewi Fatimah KURNIA**, \\ Noriaki NAKAYAMA*** and Tadato MIZOTA*** \\ *Department of Advanced Materials Science and Engineering, Graduate School of Engineering, \\ Yamaguchi University, Ube 755, Japan \\ **Research and Development Centre for Geotechnology Indonesian Institute of Sciences (LIPI), \\ Bandung, Indonesia \\ ***Department of Advanced Materials Science and Engineering, Faculty of Engineering, \\ Yamaguchi University, Ube 755, Japan
}

\begin{abstract}
Na-A type zeolite has been synthesized from the waste solution with the red mud exhausted from the Bayer process. The heats of water-vapor absorption of the Na-A and cation exchanged zeolites were measured by means of an adiabatic water-vapor absorption calorimeter which had been devised for investigating heat pump effect of zeolites. The integrated hydration enthalpy of A-zeolite is in the same order as those of mordenite and clinoptilolite. However, A-zeolite shows twice the total heat amount obtainable from unit weight samples of a natural zeolite, because natural zeolites contain impurity phases, and their dehydration amount around $100^{\circ} \mathrm{C}$ is much smaller. $\mathrm{Mg}$-exchanged Azeolite dehydrated at $100^{\circ} \mathrm{C}$ showed the largest amount of hydration enthalpy of $65.1 \mathrm{~kJ} / \mathrm{mol}$, and a weight loss on dehydration of $14.7 \%$. The $\mathrm{Mg}$-A-zeolite will be the most efficient heat pump media of all zeolites dehydrated at $100^{\circ} \mathrm{C}$ in the present work.
\end{abstract}

\section{Introduction}

Dehydrated zeolites absorb water-vapor reversibly from about 15 up to 30 weight percent. Since the vaporization enthalpy of water is larger than that of any other common refrigerants, about 10 times larger than that of freons, the zeolite-water system may provide the most efficient system as a heat pump or a heat exchanger. Although other sorbents show almost linear $\mathrm{H}_{2} \mathrm{O}$ absorption isotherms, the extremely nonlinear character of zeolites is essentially important for a zeolite solar system (Tchernev, 1978 and 1980). We have done basic research to use natural zeolites with the large hydration enthalpy. Dehydrated mordenite expels about $60 \mathrm{~kJ}$ of hydration heat when one mole of water vapor is absorbed at room temperature. Since the dehydration-hydration cycle of zeolites is reversible, the basic zeolite heat pump system could be illustrated (Fig. 1). During the day cycle, the solar heat warms up and dehydrates zeolite. The water-vapor expelled is transferred and condensed in a water-reservoir. The condensation heat should be removed from the condenser. During the night cycle, the cooled 


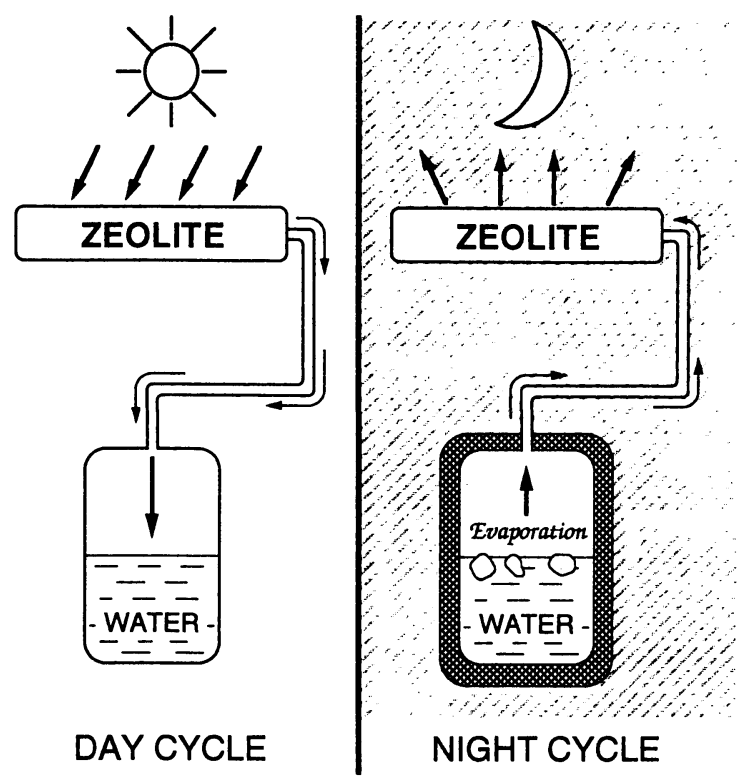

FIG. 1. Schematic illustration of day and night cycle for zeolite-water heat pump system.

zeolite absorbs water-vapor even at low vapor pressure. This accelerates the evaporation of water at the surface of the water-reservoir and hence cools the surrounding area. The zeolitewater system must be evacuated beforehand to certify vapor-convection through the system via the pipe line. Tchernev succeeded in making ice by the zeolite solar-freezing system (Tchernev, 1978 and 1980). The solar refrigerator with an efficiency of 15\% produces about $3.24 \mathrm{MJ} / \mathrm{h}$ of cooling for each square meter of collector area for a solar input of $21.6 \mathrm{MJ} / \mathrm{h}$. The system has attractive points as follows: 1) The system can be operated by sun light or by exhaust heat, anywhere without electric power. 2) The system is composed mainly of pollution-free materials such as zeolite and water, and does not exhaust chemical pollutants such as freon during operation, nor after it is discarded. 3) The materials used for the system are all widely available and cheap. Although natural zeolites are available at low cost in large amounts, inevitable contaminations such as clay minerals, quartz and feldspar degrade the efficiency as a heat reservoir. The pure synthetic zeolites are useful especially for basic research without contamination effect.

The purposes of the present study are as follows; 1 ) simple zeolite synthesis at a reasonable price, 2) to find out optimum cation-exchanged zeolites for a heat pump system, 3) to compare abilities of heat pump media for the synthetic and natural zeolites.

The strongly alkalic waste solution with the red mud exhausted from the Bayer process 
contains such a high amount of aluminum and sodium, that we attempted to synthesize zeolites by adding silica-component from reagents using a conventional autoclave as a reaction cell. We have already studied synthetic conditions such as synthetic duration and the $\mathrm{SiO}_{2} / \mathrm{Al}_{2} \mathrm{O}_{3}$ ratio (n) of the starting mixture (Kasai et al., 1993 and 1994). A special attention is focused on the relation between enthalpy of water-vapor absorption and the cation exchange of A-type zeolites for the application of a heat pump.

\section{Experimental}

\section{Preparation of sample zeolites}

Supernatant solution of red mud: Bauxite to alumina production wastes, the "red mud" which composed of the reddish solid and the strongly alkalic liquid. The alkali solution filtrated with Toyo 5C filter paper was analyzed chemically (Table 1) and was used for zeolite synthesis (Kasai et al., 1993 and 1994).

Zeolite synthesis: Starting mixtures were prepared by mixing $100 \mathrm{ml}$ sample solution with various amounts of reagent-grade sodium silicate, from $n=1$ to 10 . They were agitated at room temperature for $5 \mathrm{~h}$ in a Teflon rection bottle. Th reaction-bottle was sealed in a conventional autoclave with pressure compensation water and heated at $105^{\circ} \mathrm{C}$ for various reaction periods. The products were filtrated, washed with deionized water, and then dried at $40^{\circ} \mathrm{C}$ for $24 \mathrm{~h}$. The phases and the crystallinity of the products were examined by X-ray powder diffraction.

Cation exchange: Na-A type synthetic zeolite was served for the cation exchange experiments. The method of cation exchange was the same and common for all cation solutions: $1.0 \mathrm{~mol} / \mathrm{l}$ of aqueous solutions of $\mathrm{KCl}, \mathrm{AgNO}_{3}, \mathrm{MgCl}_{2}, \mathrm{CaCl}_{2}, \mathrm{Sr}\left(\mathrm{NO}_{3}\right)_{2}, \mathrm{CoSO}_{4}$, $\mathrm{NiCl}_{2}$ or $\mathrm{CuSO}_{4}$. The $100 \mathrm{ml}$ of each solution was poured onto $2 \mathrm{~g}$ of the $\mathrm{Na}-\mathrm{A}$ zeolite powder. The slurries were shaken at $40^{\circ} \mathrm{C}$ for $3 \mathrm{~h}$. Solid-liquid separation was done by a centrifuge. The samples were washed with deionized water and dried at $40^{\circ} \mathrm{C}$ for $24 \mathrm{~h}$. The cation-exchanged

TABLE 1. Chemical composition of two kinds of supernatant solutions of red mud.

\begin{tabular}{ccc}
\hline \multirow{2}{*}{ Element } & \multicolumn{2}{c}{ Concentration / ppm } \\
\cline { 2 - 3 } & Sample 1 & Sample 2 \\
\hline $\mathrm{Na}$ & 7110 & 15100 \\
$\mathrm{Al}$ & 1900 & 5620 \\
$\mathrm{Mo}$ & 390 & $\ldots$ \\
$\mathrm{Si}$ & 47 & 7.0 \\
$\mathrm{Fe}$ & 40 & $\cdots$ \\
$\mathrm{Ca}$ & 16 & 0.90 \\
$\mathrm{Mg}$ & 0.3 & 0.04 \\
\hline
\end{tabular}


samples were then rehydrated in a water-vapor atmosphere equilibrated with the saturated ammonium chloride solution at $25^{\circ} \mathrm{C}$. The chemical compositions of cation-exchanged zeolites were analyzed by the flame photometry for $\mathrm{Na}$ and $\mathrm{K}$ and by the atomic absorption method for other elements, using a HITACHI 170-50A atomic absorption spectrophotometer. Specimens for the analyses were prepared by dissolving into fluoboric-boric acid (Bernas, 1968; Buckley and Cranston, 1971) for samples containing $\mathrm{K}, \mathrm{Mg}, \mathrm{Co}, \mathrm{Ni}$ or $\mathrm{Cu}$. The hydrochloric acid was used for $\mathrm{Ca}$ or $\mathrm{Sr}$-exchanged samples, and the nitric acid was used for Ag-exchanged samples. X-ray powder diffraction patterns were obtained by the automated powder diffraction system with monochromated $\mathrm{Cu}-\mathrm{K} \alpha$ radiation (MAC Science $\mathrm{MXP}^{3}$ ).

\section{Hydration calorimetry}

Heat of water-vapor absorption was measured with an adiabatic water-vapor absorption calorimeter which had been devised for investigating heat pump effect of zeolites. The calorimeter (Fig. 2) is composed of a high resolution $\left(10^{-4} \mathrm{~K}\right)$ thermistor-thermometer (1) with a digital multimeter (YOKOGAWA 7561), a heater for supplying calibration heat (2), an adiabatic vessel with $400 \mathrm{ml}$ of water (3), a sample tube with a grease-less valve and a personal

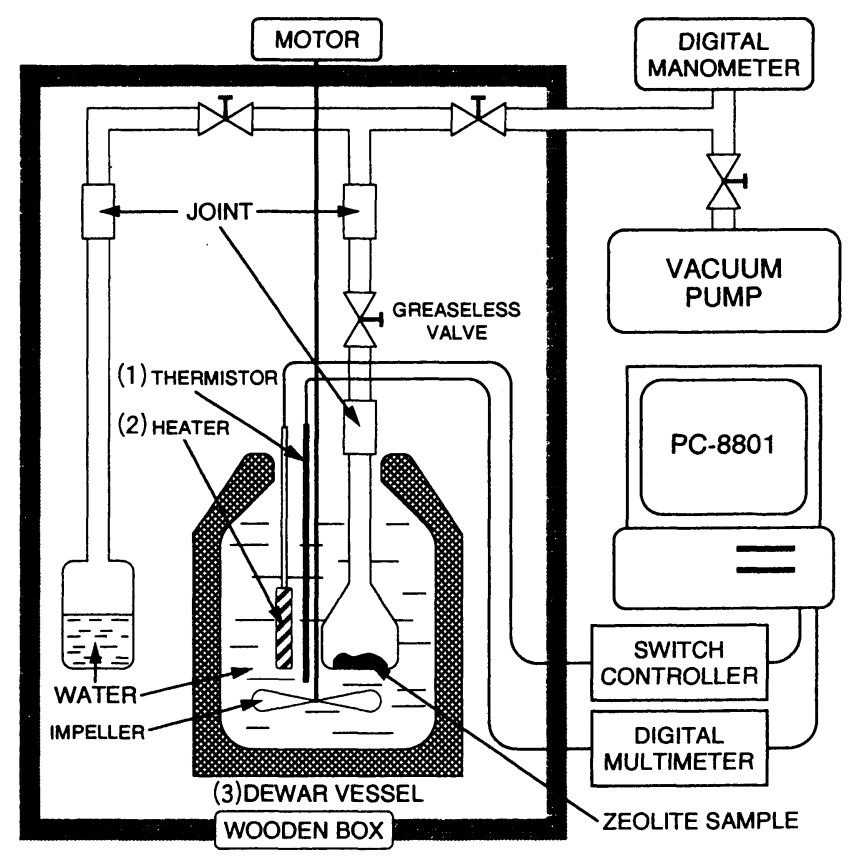

FIG. 2. Schematic view of the adiabatic calorimeter for measuring heat of absorption of water vapor with the automatic data acquisition and calibration heat-input system. 
computer system, NEC PC-8801, for data acquisition and for heat-supply control.

A $0.25 \mathrm{~g}$ of zeolite sample was dehydrated by evacuating at $100^{\circ} \mathrm{C}$ for $1 \mathrm{~h}$ in the sample tube. The amount of dehydration was obtained as the weight difference before and after the
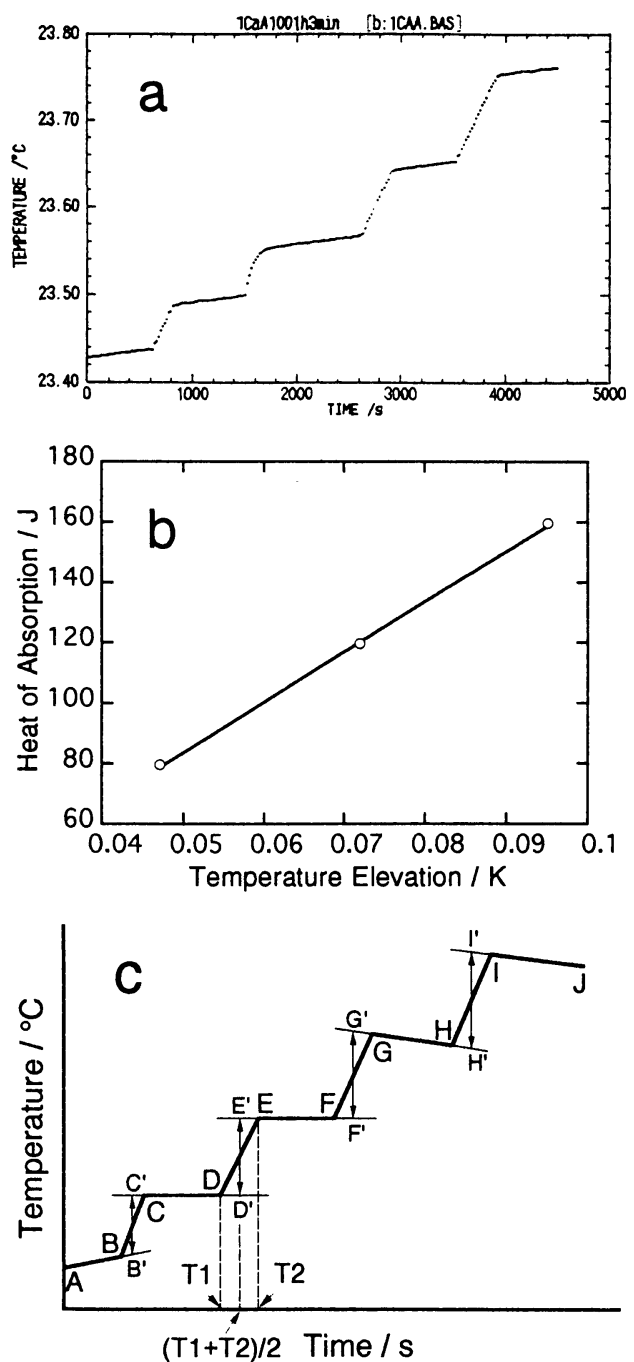

FIG. 3. An example of measurement of water vapor absorption calorimetry.

a: Temperature-time trace of the measurement, three steps by calibration heat input and a temperature elevation on hydration. b: Calibration line obtained from the measurement shown in the figure a. c: Explanation of data processing of the calorimeter system. 
dehydration by correcting evacuated air weight. The sample tube was set in the calorimeter. It takes several hours to settle the initial fluctuation in temperature before starting the calorimetric measurement.

To explain the method of data analysis, a temperature-time trace through the measurement is shown in Fig. 3a. Relatively flat traces such as $\mathrm{AB}, \mathrm{CD}, \mathrm{EF}, \mathrm{GH}$ and IJ mean the temperature equilibrium (Fig. 3c). Steps such as BC, FG and HI show the temperature elevation by the input of calibration heat. The trace DE indicates the effect of the heat evolved by hydration of zeolite. The temperature change $(\Delta T)$ for each step was obtained from the extrapolated values, such as $B^{\prime} C^{\prime}, D^{\prime} E^{\prime}, F^{\prime} G^{\prime}$ and H'I'. For example, D'E' is defined at a middle point between T1 and T2 on the time axis. The heat of water-vapor absorption was calculated from the relations between $\Delta T$ and calibration-heat (Fig. 3b).

We also measured the heat of hydration $\left(\Delta H_{w}\right)$ in liquid water-zeolite system to evaluate the consistency of the heat cycle, water/vapor/zeolitic-water. The zeolite sample was dehydrated by heating in vacuum, and then sealed in an ampoule. The ampoule was crushed in water of the adiabatic calorimeter to measure the hydration heat. The heat of evaporation $\left(\Delta H_{e}\right)$ available from a database gives self-consistent relation among $\Delta H_{v}, \Delta H_{w}$ and $\Delta H_{e}$ as follows: $\Delta H_{v}=\Delta H_{w}-\Delta H_{e}$.

\section{Results}

\section{Zeolite sample preparation}

$X$-ray diffraction measurements indicated that Na-A zeolites are obtained for $1 \leq n \leq 3$ and Na-X zeolite for $3 \leq n \leq 6$ (Kasai et al., 1994; Ciric, 1968; Lechert and Kacirek, 1991) (Table 2). Relative amounts of zeolite-components were estimated semi-quantitatively from peak heights of X-ray diffraction patterns and shown as circle size in the figure. Almost pure analcime was synthesized for $n \geq 6$. Small amount of phillipsite is found to crystallize at any

TABLE 2. Change of synthesized phases with $n=\mathrm{SiO}_{2} / \mathrm{Al}_{2} \mathrm{O}_{3}$ molar ratio in starting mixtures. Hydrothermally treated for 10 days at $105^{\circ} \mathrm{C}$.

\begin{tabular}{|c|c|c|c|c|c|c|c|c|c|c|}
\hline \multirow{2}{*}{ Zeolite phase } & \multicolumn{10}{|c|}{$n=\mathrm{SiO}_{2} / \mathrm{Al}_{2} \mathrm{O}_{3}$ ratio } \\
\hline & 1 & 2 & 3 & 4 & 5 & 6 & 7 & 8 & 9 & 10 \\
\hline \multicolumn{11}{|l|}{ Zeolite Na-A } \\
\hline \multicolumn{11}{|l|}{ Zeolite Na-X } \\
\hline Phillipsite & - & & & & • & & & & & \\
\hline Analcime & & & & & . & & & & & \\
\hline
\end{tabular}

Circle diameter indicates the semi-quantitative amount of zeolite contained. 
compositions. The amount of phillipsite was not reproducible and was fluctuated at random. Under the present synthetic conditions, the largest amount of Na-A zeolite was obtained at $n=1$. Samples synthesized at $n=1$ were used for the cation-exchange and calorimetric studies.

SEM photomicrographs (Fig. 4) of synthesized zeolites show cubic form of Na-A, octahedral crystals of Na-X (Morris et al., 1993), trapezohedral crystals of analcime with twintraces and spherical aggregates of phillipsite (Morris et al., 1993; Hansen et al., 1993), respectively. The spherical aggregate of phillipsite was observable in all products. Some spherical aggregates encapsulate Na-A cubes.

Cation exchange experiments show that $\mathrm{Na}^{+}$is completely exchanged with $\mathrm{Ag}^{+}$, whereas $\mathrm{Ni}^{2+}$ shows only 17 percent of the exchange. Other cations range from 51 to 85 percent in exchange in the present experiment (Table 3). Although the degree of exchange was variable for cations, the obtained zeolites were supplied for the hydration calorimetry. The weight loss
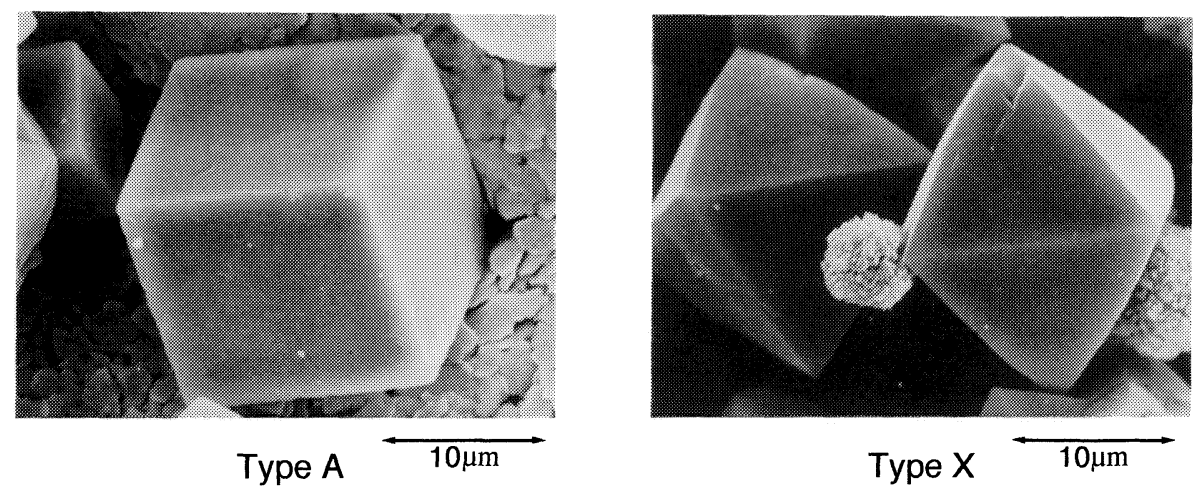

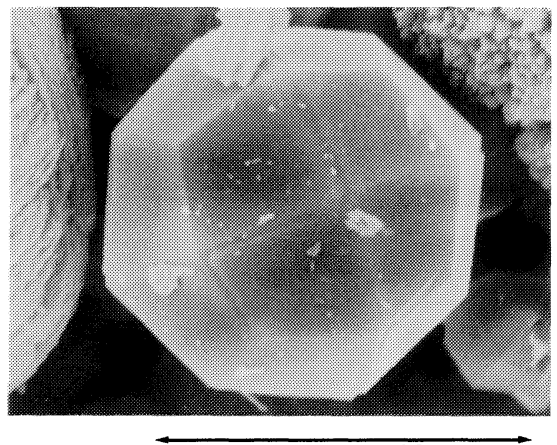

Analcime
$10 \mu \mathrm{m}$

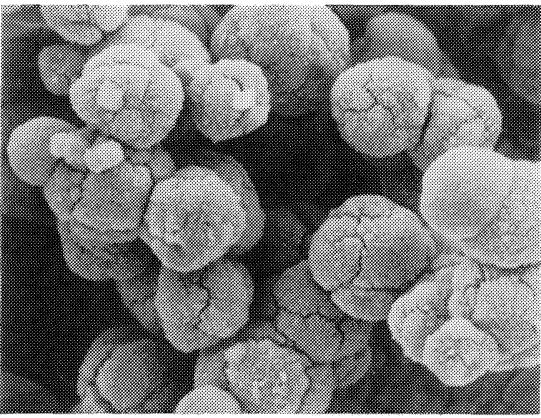

Phillipsite $\overleftrightarrow{10 \mu \mathrm{m}}$

FIG. 4. SEM photomicrographs of products from supernatant solution of red mud. 
TABLE 3. Chemical compositions of synthesized $\mathrm{Na}-\mathrm{A}$ and the cation exchanged zeolites, denoted as oxide molar ratio in the formula of $\mathrm{a}\left(\mathrm{M}_{2}^{+}, \mathrm{M}^{2+}\right) \mathrm{O} \cdot \mathrm{bNa} \mathrm{Na}_{2} \mathrm{O} \cdot \mathrm{CAl}_{2} \mathrm{O}_{3} \cdot \mathrm{dSiO}_{2} \cdot n \mathrm{H}_{2} \mathrm{O}$, and loss of weight on heating.

\begin{tabular}{|c|c|c|c|c|c|c|c|c|c|}
\hline \multirow{2}{*}{ Cations } & \multicolumn{4}{|c|}{ Oxide ratio $(\mathrm{O}=8)$} & \multirow{2}{*}{$\begin{array}{l}\text { Ratio of cation } \\
\text { exchange / \% }\end{array}$} & \multicolumn{4}{|c|}{ Loss of weight on heating / \% } \\
\hline & a & $\mathrm{b}$ & c & d & & $\begin{array}{l}\text { Under vaccum } \\
25 \sim 100^{\circ} \mathrm{C}\end{array}$ & $25 \sim 1000^{\circ} \mathrm{C}$ & $25 \sim 500^{\circ} \mathrm{C}$ & $25 \sim 800^{\circ} \mathrm{C}$ \\
\hline $\mathrm{Na}^{+}$ & 0.00 & 1.03 & 1.00 & 2.00 & 0 & 14.0 & 3.72 & 20.1 & 21.6 \\
\hline $\mathrm{K}^{+}$ & 0.83 & 0.15 & 0.99 & 1.93 & 85 & 9.12 & 2.69 & 16.9 & 17.8 \\
\hline $\mathrm{Ag}^{+}$ & 1.09 & 0.00 & 1.09 & 2.54 & 100 & 11.7 & 2.51 & 11.6 & 14.2 \\
\hline $\mathrm{Mg}^{2+}$ & 0.49 & 0.48 & 1.00 & 1.99 & 51 & 14.7 & 7.19 & 22.8 & 25.9 \\
\hline $\mathrm{Ca}^{2+}$ & 0.82 & 0.22 & 1.01 & 2.01 & 78 & 9.41 & 3.55 & 20.3 & 21.6 \\
\hline $\mathrm{Sr}^{2+}$ & 0.73 & 0.22 & 1.09 & 2.67 & 77 & 9.94 & 3.68 & 20.4 & 22.1 \\
\hline $\mathrm{Co}^{2+}$ & 0.50 & 0.46 & 0.98 & 1. 92 & 52 & 11.8 & 8.19 & 23.4 & 25.2 \\
\hline $\mathrm{Ni}^{2+}$ & 0.13 & 0.62 & 0.94 & 1.78 & 17 & 20.8 & 4.76 & 23.0 & 24.5 \\
\hline $\mathrm{Cu}^{2+*}$ & 2. 36 & 0.05 & 1.20 & 2. 73 & 98 & ... & 10.4 & 25.9 & 34.7 \\
\hline
\end{tabular}

* : Na-A zeolite is completely decomposed by $\mathrm{Cu}^{2+}$-exchange.

on heating depends on individual cation type. Unusually high weight loss is observed for $\mathrm{Cu}^{2+}$ exchanged sample. X-ray diffraction pattern of each sample coincides with that of A-type zeolite except $\mathrm{Cu}$-exchanged one (Fig. 5). This indicates that the $\mathrm{Cu}$-exchange decomposes zeolite structure and forms copper sulfate hydroxide, $\mathrm{Cu}_{4} \mathrm{SO}_{4}(\mathrm{OH})_{6}$.

\section{Hydration calorimetry}

The integrated heat of absorption per 1 mole of absorbed water-vapor $\left(\Delta H_{v}\right)$ was calculated from the hydration heat and the weight difference between samples before and after hydration. The values of $\Delta H_{v}$ for $\mathrm{Na}-\mathrm{A}$ and cation exchanged samples range from 60 to $66 \mathrm{~kJ} /$ mol (Table 4). Reproducibility of the enthalpy values is within $\pm 1.5 \mathrm{~kJ} / \mathrm{mol}$ in this study.

Both the large hydration amount and the large molar heat of absorption of water-vapor are favorable for the application of zeolite as a heat pump media. Total heat amount $(Q)$ obtainable from $1 \mathrm{~kg}$ of zeolite sample was calculated (Table 4 ) for this purpose. The maximum $Q$ value was $531 \mathrm{~kJ} / \mathrm{kg}$ for $\mathrm{Mg}^{2+}$ exchange zeolite, when it was dehydrated at $100^{\circ} \mathrm{C}$. This value is about 9 percent greater than that of the $\mathrm{Na}-\mathrm{A}, 488 \mathrm{~kJ} / \mathrm{kg}$. This indicates that $\mathrm{Mg}^{2+}$ exchanged zeolite is the most suitable heat reservoir among all samples treated in the present study. Table 5 shows the $\Delta H_{v}$ and $Q$ values for mordenite samples from Koromogawa, Iwate prefecture, Japan, and from Cikalong, west Java, and for clinoptilolite from Bogor, west Java, Indonesia. The $\Delta H_{v}$ value of natural zeolite, such as mordenite and clinoptilolite, was of the same order to that of zeolite A samples. However, the $Q$ values were smaller than those of zeolite A samples, because the natural zeolites include impurity phases such as clay minerals and quartz; and show relatively low dehydration amounts at low temperatures around $100^{\circ} \mathrm{C}$.

The mordenite sample from Koromogawa showed the $\Delta H_{w}$ value of $-18.5 \mathrm{~kJ} / \mathrm{mol}$ and the $\Delta H_{v}$ value of $-60.0 \mathrm{~kJ} / \mathrm{mol}$, when it was dehydrated at $120^{\circ} \mathrm{C}$. These values give the evaporation 


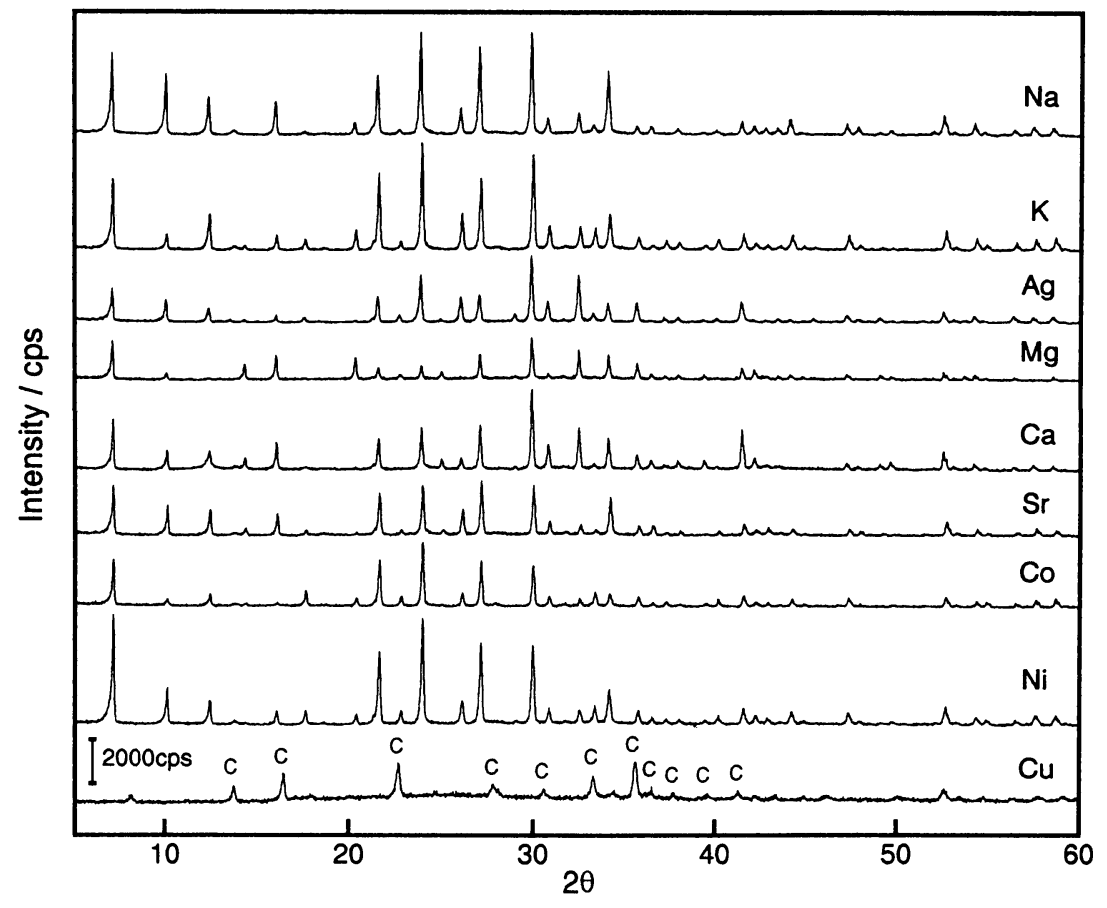

FIG. 5. X-ray diffraction patterns of synthesized Na-A zeolite and cation exchanged zeolites. C: Copper sulfate hydroxide, $\mathrm{Cu}_{4} \mathrm{SO}_{4}(\mathrm{OH})_{6}$.

TABLE 4. Integrated molar enthalpy of water vapor absorption and the ratio of rehydration of type A zeolite and of cation exchanged zeolites. $\Delta H_{v}$ : integrated heat of absorption of $\mathrm{H}_{2} \mathrm{O}(\mathrm{g})$ at $23 \sim 25^{\circ} \mathrm{C} . Q$ : heat of water vapor absorption per $1 \mathrm{~kg}$ of zeolite.

\begin{tabular}{cccc}
\hline Guest cation & Rehydration $/ \%$ & $-\Delta H_{v} / \mathrm{kJ} \cdot \mathrm{mol}^{-1}$ & $Q / \mathrm{kJ} \cdot \mathrm{kg}^{-1}$ \\
\hline $\mathrm{Na}^{+} *$ & 102 & 63.0 & 488 \\
$\mathrm{~K}^{+}$ & 86.2 & 65.1 & 330 \\
$\mathrm{Ag}^{+}$ & 88.1 & 59.6 & 342 \\
$\mathrm{Mg}^{2+}$ & 87.4 & 65.1 & 531 \\
$\mathrm{Ca}^{2+}$ & 102 & 66.2 & 345 \\
$\mathrm{Sr}^{2+}$ & 108 & 65.7 & 362 \\
$\mathrm{Co}^{2+}$ & 70.1 & 63.3 & 413 \\
$\mathrm{Ni}^{2+}$ & 66.4 & 65.6 & 489 \\
\hline
\end{tabular}

*: Original Na-A zeolite 
TABLE 5. Integrated molar enthalpy of water vapor absorption $\left(\Delta H_{v}\right)$ of natural zeolites from Koromogawa, Iwate Pref. Japan, and Cikalong and Bogor, west Java Indonesia measured at $23 \sim 25^{\circ} \mathrm{C}$. $Q$ : heat of water vapor absorption per $1 \mathrm{~kg}$ of zeolite.

\begin{tabular}{ccccc}
\hline $\begin{array}{c}\text { Temperature of } \\
\text { dehydration } /{ }^{\circ} \mathrm{C}\end{array}$ & $\begin{array}{c}\text { Sampling } \\
\text { locality }\end{array}$ & Main component & $-\Delta H_{v} / \mathrm{kJ} \cdot \mathrm{mol}^{-1}$ & $Q / \mathrm{kJ} \cdot \mathrm{kg}^{-1}$ \\
\hline \multirow{2}{*}{100} & Koromogawa & Mordenite & 58.8 & 237 \\
& Cikalong & Mordenite & 63.4 & 222 \\
& Bogor & Clinoptilolite & 61.1 & 197 \\
\hline 120 & Koromogawa & Mordenite & 60.0 & 257 \\
\hline
\end{tabular}

enthalpy to be $-18.5-(-60.0)=41.5 \mathrm{~kJ} / \mathrm{mol}$ by using the self-consistency relation, $\Delta H_{e}=\Delta H_{w^{-}}$ $\Delta H_{v}$. Since the true value of $\Delta H_{e}$ is quoted to be $44.0 \mathrm{~kJ} / \mathrm{mol}$ at $25^{\circ} \mathrm{C}$, the mismatch of $2.5 \mathrm{~kJ}$, will be due to the error of measurements of either $\Delta H_{v}$ or $\Delta H_{w}$.

\section{Conclusions}

Several kinds of zeolites have been synthesized hydrothermally at $105^{\circ} \mathrm{C}$ from the waste solutions of red mud exhausted in the Bayer process in an alumina production industry by adding sodium silicate as a silica component. The $\mathrm{SiO}_{2} / \mathrm{Al}_{2} \mathrm{O}_{3}$ ratios $(n)$ for the starting mixture significantly influenced the kind of product-phases. Main products were of $\mathrm{Na}$-A zeolite at $n=1$ and 2, Na-X zeolite at $n=3-5$ and analcime at $n=6-10$. Phillipsite was crystallized in the same condition in which Na-A or Na-X zeolite was synthesized. The amount of phillipsite was not reproducible in the present syntheses.

The hydration enthalpy of $\mathrm{Na}-\mathrm{A}$ type and the cation exchanged zeolites ranges from 60 to $66 \mathrm{~kJ} / \mathrm{mol}\left(\mathrm{H}_{2} \mathrm{O}\right)$. The maximum value of total heat amount $(Q)$ obtainable from $1 \mathrm{~kg}$ of zeolite was $531 \mathrm{~kJ} / \mathrm{kg}$ for $\mathrm{Mg}^{2+}$ exchanged A-zeolite. This value is about 9 percent greater than that of the Na-A, $488 \mathrm{~kJ} / \mathrm{kg}$. The $\mathrm{Mg}^{2+}$ exchanged A-zeolite is the most suitable heat reservoir among all the samples treated in the present study.

Integrated hydration enthalpy of natural zeolites, such as mordenite and clinoptilolite, was almost the same as that of A-zeolite. But the $Q$-values of natural zeolites were about half of that of A-zeolite samples because of the presence of impurity phases, and the insufficient dehydration characters at the relatively low temperature region around $100^{\circ} \mathrm{C}$.

Acknowledgements-The authors express their thanks to former Prof. K. Takahashi for his critical discussions. We appreciate many supports by K. Fujiwara for chemical analyses. 


\section{References}

Bernas, B. (1968) A New Method for Decomposition and Comprehensive Analysis of Silicates by Atomic Absorption Spectrometry. Anal. Chem., 40, 1682-1686.

BuCKLey, D.E. and Cranston, R.E. (1971) Atomic Absorption Analysis of 18 Elements from a Single Decomposition of Aluminosilicate. Chemical Geology, 7, 273-284.

CIRIC, J. (1968) Kinetics of Zeolite A Crystallization. J. Colloid Interface Sci., 28, 315-324.

HANSEN, S., HAKANSSON, U., LANDA-CANOVAS, A.R. and FALTH, L. (1993) On the Crystal Chemistry of NaP Zeolites. Zeolites, 13, 276-280.

Kasai, T., Maeda, H., Matsui, K., Gondou, S., Mizota, T. and TaKahashi, K. (1994) Synthesis and Characterization of Zeolites from Alkali Solution Wasted from Bauxite Processing. Proc. of the MMIJ/ Aus IMM Joint Symposium, 251-258.

KASAI, T., MizOTA, T. and TAKAHASHI, K. (1993) Waste Materials Utilization of Red Mud from Bayer Process, Recovery of Rare Metals and Zeolite-synthesis. Proc. Mat. for Properties, H. Henein and T. Oki eds., 165-168.

LECHERT, H. and KACIREK, H. (1991) Investigations on the Crystallization of X-type Zeolites. Zeolites, 11, 720728.

MORRIS, M., DiXon, A.G., SACCO, A., JR. and ThOMPSON, R.W. (1993) Investigations on the Relative Effectiveness of Some Tertiary Alkanolamines in the Synthesis of Large-crystal Zeolite NaA. Zeolites, 13, 113-121.

TCHERNEV, D.I. (1978) Solar Energy Application of Natural Zeolites. Natural Zeolites, L.B. Sand and F.A. Mumpton eds., Pergamon, Oxford, 479-485.

TCHERnEV, D.I. (1980) The Use of Zeolites for Solar Cooling. Proc. 5th Int. Conf. on Zeolite, Rees, L.V.C. ed., 788-794.

Received September 12, 1994; accepted October 28, 1994 